\title{
Localization of the organic matter production and degradation in two different estuaries
}

\author{
Anna Vazhova $^{1, *}$ and Yury Zuenko ${ }^{1}$ \\ ${ }^{1}$ Pacific Branch of Russian Federal Research Institute of Fisheries and Oceanography (TINRO), \\ Vladivostok, Russia
}

\begin{abstract}
Physical and chemical processes related to primary production of the estuaries of two rivers with different water regime are considered with special attention to their spatial and seasonal variability. Both production and degradation of the organic matter are quantitatively evaluated on the data of non-conservative variation of dissolved inorganic phosphorus concentration in the process of the river water dilution. Contribution of recycling to the phosphorus balance and the estuarine waters productivity is estimated. The organic matter degradation prevailed in the internal part of both estuaries, but its production dominated in their external parts, with a tendency of production lowering and degradation strengthening from spring to autumn. Utilization of the re-mineralized phosphorus in the external estuaries increased their potential productivity by $20-50 \%$, provided by the terrigenous flux with the river water.
\end{abstract}

\section{Introduction}

Estuarine systems are the most productive natural ecosystems in the world. They house the highest phytoplankton and zooplankton concentrations, are important end points for freshwater runoff and pollution, and generally serve dense human settlements. The high biological productivity of estuaries is obviously largely supported through a permanent nutrient influx of terrestrial origin. Besides, recent studies highlight an importance of regenerated productivity entering to the estuarine ecosystems through destructive processes of organics (Sapozhnikov et al., 2018; Pettit et al., 2016). The production/destruction processes have strong spatial and seasonal variability that can be seen in the nutrients dynamics (Eyre, Balls, 1999; Boonphakdee, Fujiwara, 2008; Suzal et al., 2008; Sarma et al., 2010; Lapin, 2011; Statham, 2012; Vazhova, Zuenko, 2015; and others). To date, the balance between production and degradation is evaluated by indirect chemical methods in many estuaries of different types, such as the Para Lagoon (Krasnick, Caperon, 1973), tidal estuaries of the Sheldt, Gironde and Sado (Cabecadas et al., 1999) and the Bristol Channel (Joint, Pomroy, 1981), tropical estuaries of the Mandovi-Zuari (Krishna Kumari et al., 2002) and the Bangpakong (Boonphakdee, Fujiwara, 2008), subtropical estuaries of the Ebro (Cruzado et al., 2002) and Douro (Azevedo et al., 2006), monsoon estuary of the Razdolnaya/Suifen (Zvalinsky et al., 2005), polar estuary of the Ob (Lapin, 2011), and

\footnotetext{
*Corresponding author: anna.vazhova@gmail.com
} 
others. In few cases, the same approach is used for approximate assessment of primary production (Underwood, Kromkamp, 1999; Cloern et al., 2014). However, the patterns of spatial and seasonal variability of bioproductivity in the estuaries are still not clear. Direct measurements of production and destruction using the classic incubation techniques are too complicated, so their results are very scarce and local in space and time and sometimes controversial (Caffrey, et al., 2014; Semkin et al., 2015; Oczkowski et al., 2016). The destruction rate is usually not evaluated at all and not accounted in the productivity studies. Mechanisms of the production and degradation spatio-temporal dynamics are unknown. Bioproductivity processes can be traced through spatial dynamics of chemical parameters (Zvalinsky et al., 2005; Telesh, Khlebovich 2010). This methodology allows calculating the difference between production and destruction as the deviation of observed nutrients concentrations from their "potential" concentrations determined by the river water dilution. However, contribution of recycling is not usually evaluated, and all nutrients in the estuary are considered as the terrigenous stock (Krishna Kumari et al., 2002; Lapin, 2011; Statham, 2012).

Considering the abovementioned problems of traditional approaches, the main goals of this study were:

- to define regularities of spatial heterogeneity of the organic matter production and destruction within two estuaries belonged to the rivers with different water regime;

- to divide the areas of active production and mineralization within the estuarine continuum and assess their seasonal dynamics.

The novelty of the study consists in separate quantification of both production and destruction that allows avoiding methodical underestimation of primary production.

\section{Materials and methods}

\subsection{Surveyed area}

Two estuaries of the rivers entering to Peter the Great Bay (western Japan Sea) were monitored in 2010-2013: one of the largest rivers of the Japan Sea basin known as the Razdolnaya in Russia and as the Suifen in China, and the small mountain river named Sukhodol. The mean annual water discharge is approximately $2.46 \mathrm{~km}^{3}$ for the Razdolnaya/Suyfen and $0.14 \mathrm{~km}^{3}$ for the Sukhodol (Savelyev et al., 2005; Budaeva et al., 2013). In conditions of monsoon climate with dry winter and rainy summer, the main part of annual runoff (70-90\%) is discharged in April-September.

\subsection{Sample processing}

The chemical surveys in the estuaries were conducted on August 30, 2010, June 30, 2011, May 22, 2012, October 31, 2012, and September 10, 2013 in the Razdolnaya/Suyfen and on August 4, 2010, July 5, 2011, August 25, 2011, April 25, 2012, August 8, 2012, September 4, 2012, October 25, 2012, and December 25, 2012 in the Sukhodol (Fig. 1). The stations of the surveys were located over the whole estuarine area between the rivers and the sea, including tributaries and secondary streams, but the most distinctive changes of parameters were observed along the main flows.

Temperature and salinity profiles from the water surface to the bottom were measured by the oceanographic probe YSI-6600V2. Water samples for laboratory measurements of the dissolved inorganic phosphorus concentration (DIP) were taken in dark polyethylene bottle at the surface and at the bottom (for depth $>1 \mathrm{~m}$ ) by Niskin sampler. The samples 
were processed in laboratory using Shimadzu UV-1800 spectrophotometer, following the standard protocols for Murphy-Riley method (Methods of seawater analysis..., 1999, Grasshoff et al., 2007).

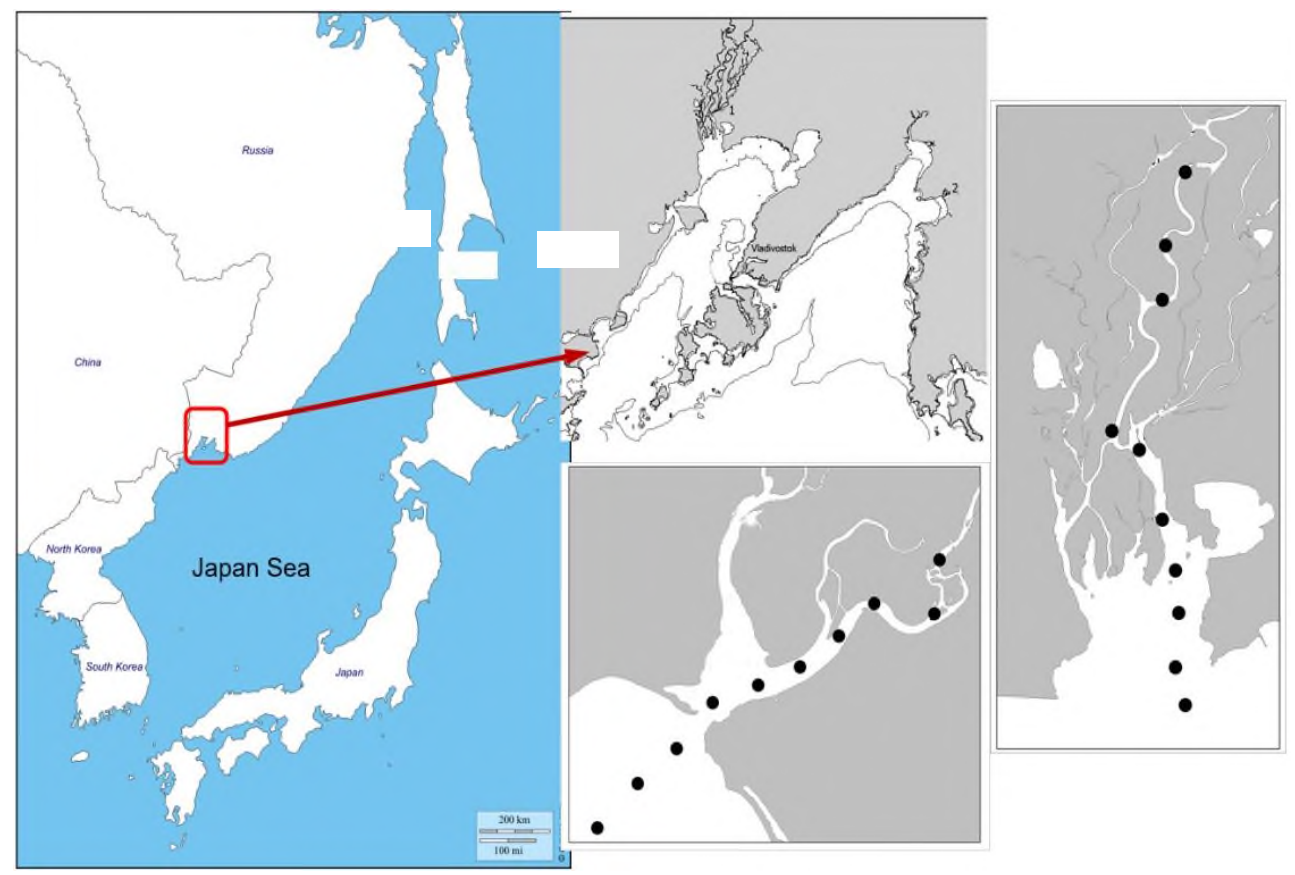

Fig. 1. Scheme of the surveyed estuaries location: Razdolnaya/ Suyfen (1) and Sukhodol (2).

\subsection{Calculation method}

Both estuaries were divided to the internal and external zones by salinity in their surface and subsurface layers. In the internal zone, there are the fresh river water in the surface layer and the brackish water in the saline cline at the bottom. In the external zone, there is the brackish water plume at the estuary surface and the salted marine water in the subsurface layer. The boundary between the internal and external parts of estuary is usually close to the river bar, but declines from the bar in both directions are possible: it shifts upstream from spring to summer and downstream from summer to autumn, following seasonal fluctuations of the sea level (Fig. 2) (Vazhova, Zuenko, 2015). 


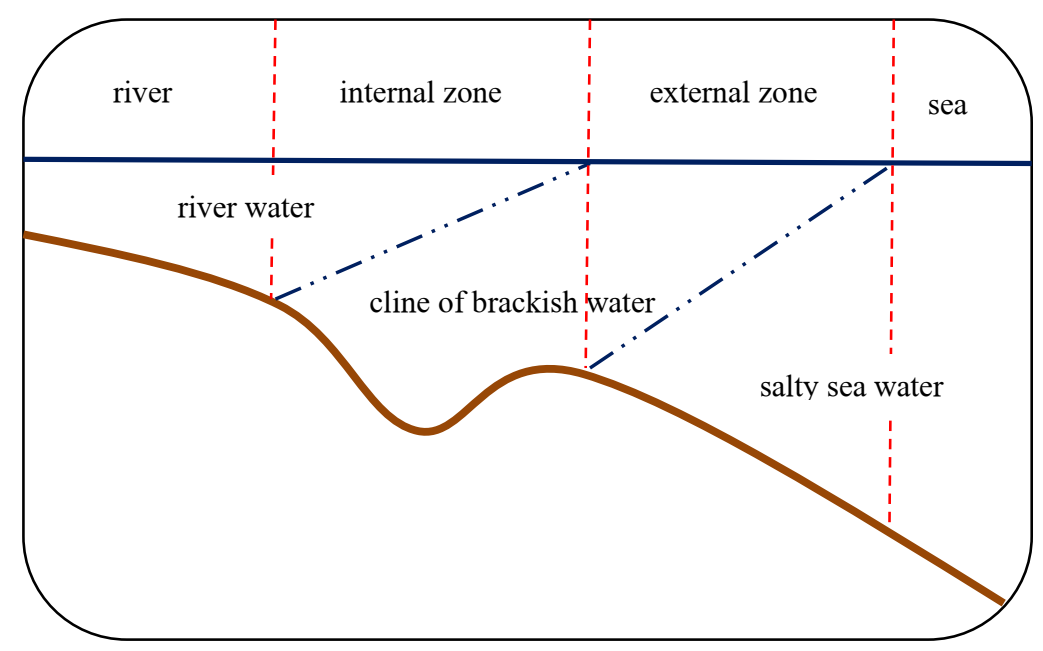

Fig. 2. Scheme of the water structure in the estuary.

Deviations of observed DIP values from the potential values conditioned by dilution of river water are caused by the phosphorus utilization for photosynthesis or its remineralization (Lebo, Sharp, 1992; Zvalinskiy et al., 2005). Without production or degradation, its concentration must change proportionally to salinity increase that is considered as the conservative behavior: DIP is a linear function of salinity in this case. Any deviation of DIP from this linear dependence (straight line on the salinity-DIP diagrams) indicates the process of organic matter production (if deviation is a decrease) or degradation (if deviation is an increase). This approach is used usually for the case of two water masses mixing: freshwater (rich in nutrients) and saltwater (poor in nutrients). We improved the method for the case of three water masses by adding the subsurface seawater (saline, nutrient-rich) because of its significant impact on nutrients concentration in the external estuaries. In this case, the potential DIP values have a non-linear dependence on salinity, but they can be determined from the ratio between the initial water masses in their mixture calculated by the TS-analysis method, using the so called triangle of mixing (Mamaev, 1987; Fig. 3). The simple linear dependence of the potential concentration on salinity is quite accessible for the internal estuaries, but overestimates the degradation assessments in the external estuaries. 


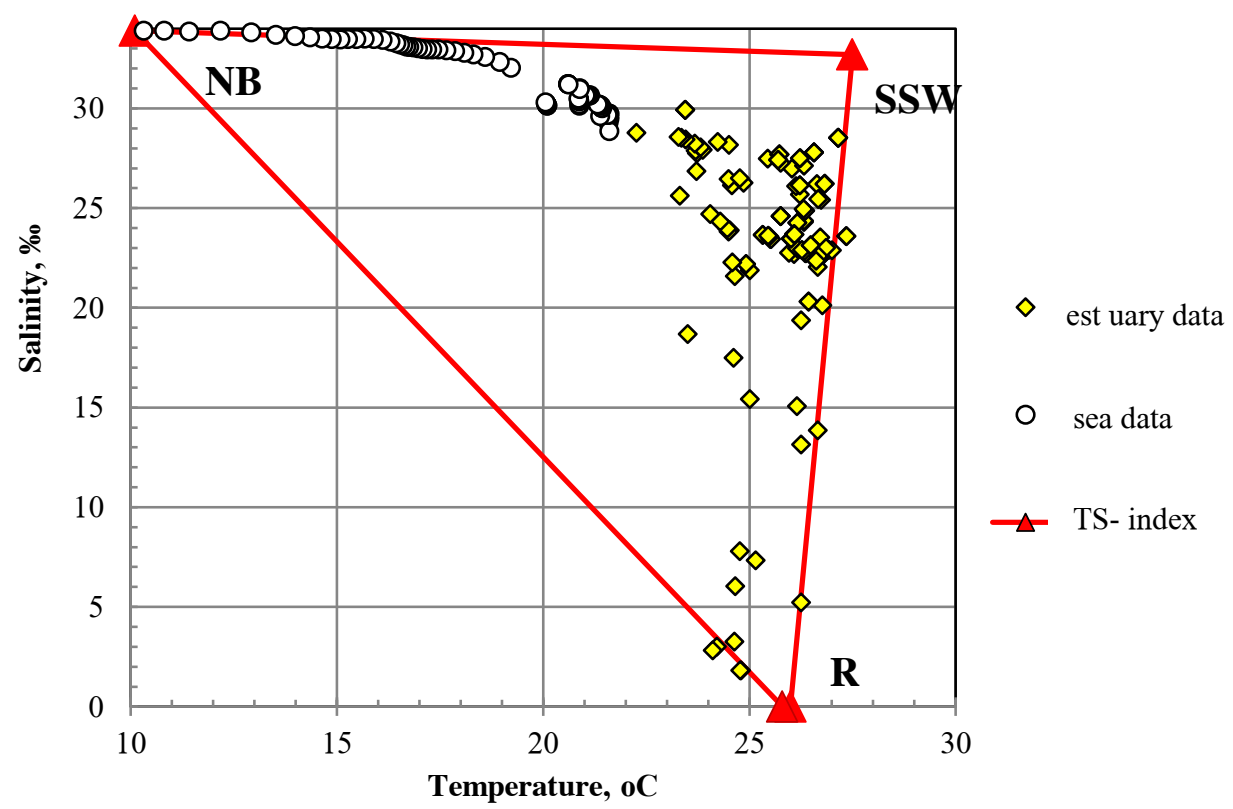

Fig. 3. An example of a TS-spot diagram for the Sukhodol estuary, which was used to determine the degree of dilution of river waters (R) by sea (SSW - surface sea water and NB - near-bottom shelf waters).

Positive deviations of DIP from its potential values at each site/station $(i)$ are re-calculated to production $\boldsymbol{b}_{\boldsymbol{i}}$ (in carbon units) using the Redfield ratio between carbon and phosphorus in organic matter (C: $\mathrm{P}=40: 1$, from Redfield et al., 1963, Sterner, Elser 2002):

$$
\boldsymbol{b}_{i}=\boldsymbol{R} \cdot\left(\boldsymbol{C}_{\boldsymbol{i} \text { potential }}-\boldsymbol{C}_{\boldsymbol{i}}\right) \quad\left[\mathrm{gC} \mathrm{m}^{-3}\right],
$$

where: $b$ - new organic matter weight, or production (in carbon units);

$C$ - measured DIP concentration;

$\mathrm{C}_{\text {i potential }}$ - potential DIP concentration;

$R$ - Redfield ratio.

Then the yield of organic matter from a unit volume of the river water $(\mathbf{Y})$ is calculated. This yield is produced by the unit volume of the river water within the time of its destination to the station $i$, taking into account dilution of the river water by the saltwater in the estuary:

$$
\boldsymbol{Y}_{\boldsymbol{i}}=\boldsymbol{b}_{\boldsymbol{i}} / \boldsymbol{\mu}_{\boldsymbol{i}} \quad\left[\mathrm{gC} \mathrm{m}^{-3} \text { river water }\right],
$$

where $\mu$-portion of the river water in the mixture (determined by TS-analysis).

By its definition, the value of $\boldsymbol{Y}$ may increase only downstream. If the formal calculation provides a negative value, it is interpreted as the prevalence of degradation. For such cases, the minimal estimate of degradation $\boldsymbol{d}_{i}$ is calculated from the following equations with the assumption that the production $\boldsymbol{b}_{\boldsymbol{i}}=0$ at these station:

$$
\begin{gathered}
\boldsymbol{b}_{i}=0=\boldsymbol{R} \cdot\left(\boldsymbol{C}_{\text {i potential }}+\boldsymbol{D}-\boldsymbol{C}_{i}\right) \quad\left[\mathrm{gC} \mathrm{m}^{-3}\right], \\
\boldsymbol{d}_{i}=\boldsymbol{R} \cdot \boldsymbol{D}\left[\mathrm{gC} \mathrm{m}^{-3}\right],
\end{gathered}
$$

where $D$ - amount of mineralized DIP.

For the cases of monotonous downstream decreasing of the river water portion in the mixture, primary production per a unit of the estuary length can be estimated. It is 
calculated using the difference of the yield from a unit volume of the river water and the distance between neighbor stations in the downstream direction.

$$
\boldsymbol{p}_{\boldsymbol{i}}=\frac{\boldsymbol{Y}_{\boldsymbol{i}}-\boldsymbol{Y}_{\boldsymbol{i}-1}}{\boldsymbol{L}_{\boldsymbol{i}}-\boldsymbol{L}_{\boldsymbol{i}-1}} \times \mu_{\boldsymbol{i}} \quad\left[\mathrm{gC} \mathrm{\textrm {g } ^ { - 3 }} \mathrm{km}^{-1}\right],
$$

where: $\left(L_{i}-L_{i-1}\right)-$ distance between stations

$\left(Y_{i}-Y_{i-1}\right)$ - difference of the yield

$\mu$ - portion of the river water

The value of primary production in ordinary terms (primary production per a day $\boldsymbol{P}$ )) can be evaluated approximately knowing the velocity of the river flow:

$$
\boldsymbol{P}=\boldsymbol{p} \cdot \boldsymbol{v}\left[\mathrm{gC} \mathrm{m}^{-3} \mathrm{~d}^{-1}\right],
$$

where $\boldsymbol{v}$ - velocity of the river flow

$\boldsymbol{p}$ - primary production per a unit of the estuary length.

If the flow velocity was not measured, it can be roughly estimated from the data on fresh water discharge:

$$
\boldsymbol{v}=\boldsymbol{Q} /(\boldsymbol{b} \cdot \boldsymbol{h})\left[\mathrm{km} \mathrm{d}^{-1}\right],
$$

where $Q$ - water discharge volume,

$b$ - width of the estuary channel,

$h-$ thickness of the fresh water layer.

The principle of monotonous increasing of production and cumulative degradation from a unit volume of the river water provides us a possibility to evaluate these opposing processes separately. There is a predominance of one or another of them in certain parts of the estuaries, and the reverse process can be neglected for a rough estimate. However, it should be noted that this method allows us to evaluate only the minimal levels of both processes.

It is important to note that the calculation of primary production was not the main task in this study. However, rough estimates can be obtained on the basis of the balance of phosphorus entered directly to the point where the measurements were made. So far as the runoff of both rivers is highly variable, its mean annual values can be used only as general characteristics of the rivers discharge. Thus, the results of calculations using the mean annual values of the runoff can be considered as very approximate estimates only.

\section{Results}

Salinity at the surface of the Sukhodol estuary usually begins to increase in 1-2 km to the bar; the fresh river water reaches the bar only during the floods. In the Razdolnaya estuary, the salinity starts to increase in $2-5 \mathrm{~km}$ to the bar in summer, but the fresh river water reaches the bar in the spring and autumn when sea level is low (Fig. 4, 5). 

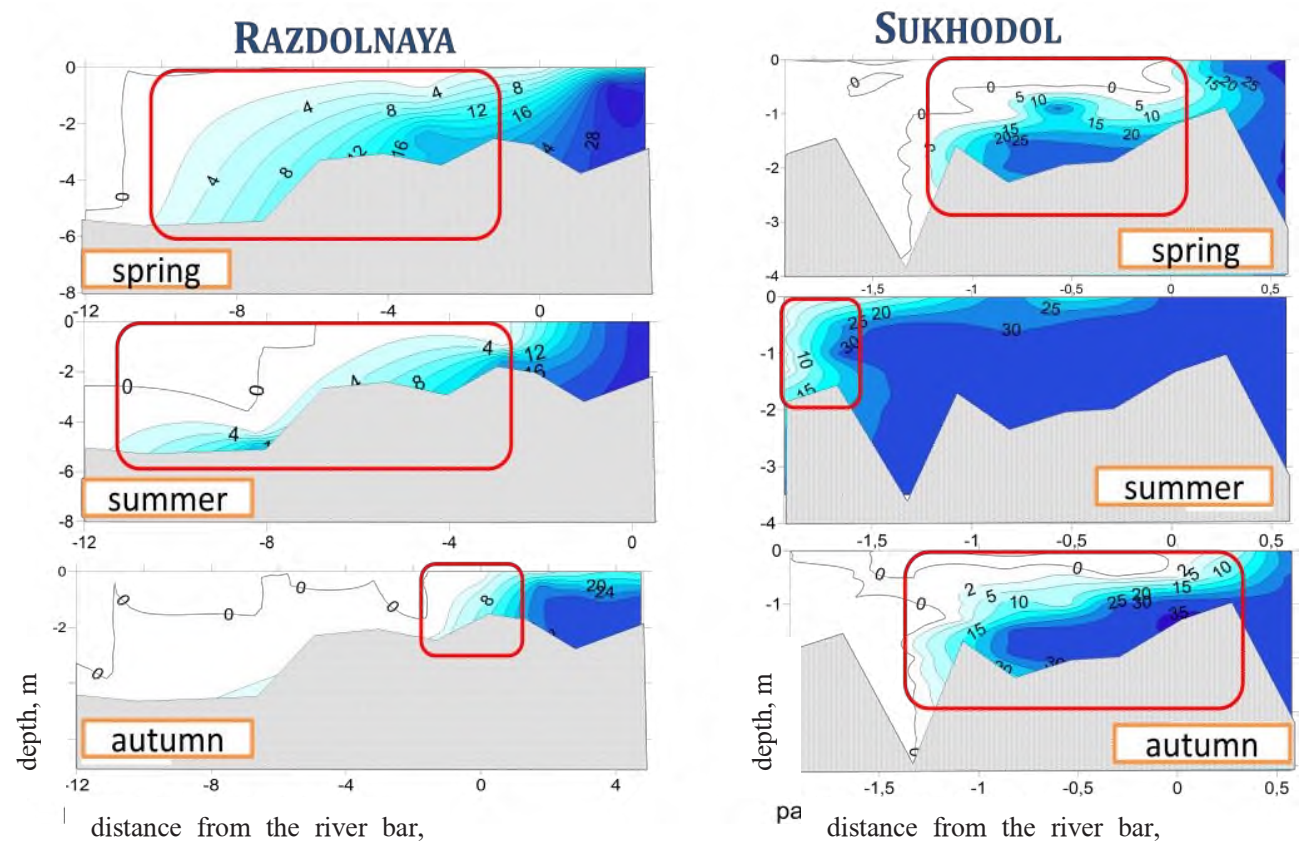

Fig. 4. Vertical distribution of salinity (psu) in the estuaries, averaged by season. The zone of the internal estuary is marked.

In the external parts of both estuaries, the observed values of DIP are lower than the potential values: on average $0.2-0.3,0.8-1.5$, and $1.0-1.2 \square \mathrm{M}$ against $0.5, \sim 2.0$, and $\sim 1.4$ $\square \mathrm{M}$ for the Razdolnaya in spring, summer, and autumn, respectively, and $0.2-0.5,0.4-0.5$, and $0.5 \square \mathrm{M}$ against $0.8-1.3, \sim 0.7$, and $0.8-1.0 \square \mathrm{M}$ for the Sukhodol in spring, summer, and autumn, respectively (Fig. 5).

This lack of nutrients indicates predominance of the production processes in this zone. In spring, the zone of production prevalence extends over almost entire estuaries, in particular for the Razdolnaya/Suifen, but the maximum difference between observed and potential levels of DIP is permanently observed in the external estuary. On the contrary, factual DIP values are usually higher than the potential ones in the internal part of both estuaries that means that the organic matter degradation prevails there over its production. In autumn, the zone of DIP above the conservative values extends and the organic matter degradation prevails in general. Both production and degradation processes are weakened in autumn and winter. 

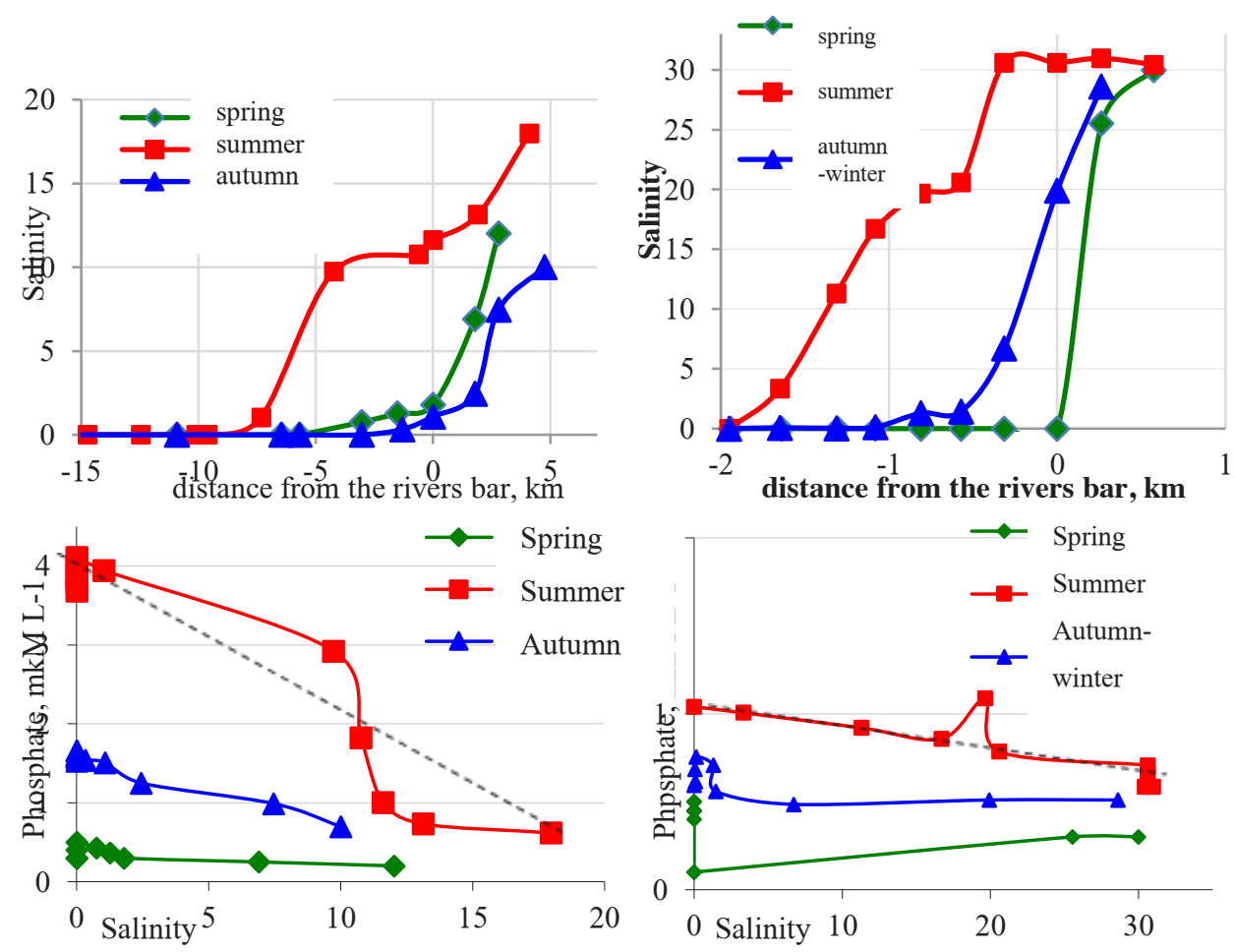

Fig. 5. Salinity at the surface of the Razdolnaya/Suyfen (left) and Sukhodol (right) estuaries, averaged by season, and dependence of mineral phosphorus concentration on salinity for the surface layer of both estuaries. Examples of conservative behavior of the phosphorus concentration (strait dashed line) are shown for the summer season.

Each unit volume of the river water as it passes through the estuary (with gradual increasing of the volume because of its mixing with the seawater) produces a gradually increasing amount of organic matter until the total utilization of terrigenous nutrients. Finally, each cubic meter of the river water of both rivers produces 3-5 gC in summer and 0.5-1.0 $\mathrm{gC}$ in spring and autumn. In addition, the amount of re-mineralized phosphorus from a unit volume of the river water increases gradually, too (Fig. 6). That happens in both estuaries, but more actively in the Sukhodol estuary, in particular in summer (Fig.7).

The maximum values of primary production per a unit of estuary length are comparable for both estuaries: 0.9-1.2 $\mathrm{gC} \mathrm{m}^{-3} \mathrm{~km}^{-1}$ in the Sukhodol in spring and fall and in the Razdolnaya/Suifen in summer, with the maximum at the front between the internal and external zones (Fig. 7). However, seasonal variations of production are different: in the Razdolnaya/Suifen, the production decreases in spring and autumn $\left(<0.2 \mathrm{gC} \mathrm{m}^{-3} \mathrm{~km}^{-1}\right)$ because of seasonal lack of nutrients, the summer peak of production is conditioned here by nutrient-rich flood waters, but the Sukhodol waters are nutrient-rich in spring, then their productivity decreases gradually. These values of production per a unit of estuary length correspond approximately to the daily primary production values of $0.0-5.6 \mathrm{gC} \mathrm{m}^{-3} \mathrm{~d}^{-1}$ and 0.1-4.6 $\mathrm{gC} \mathrm{m}^{-3} \mathrm{~d}^{-1}$ in different parts of the estuaries in summer (Fig. 8), assuming the river discharge close to the mean summer levels of $120 \mathrm{~m}^{3} \mathrm{~s}^{-1}$ for the Razdolnaya/Suifen and 10 $\mathrm{m}^{3} \mathrm{~s}^{-1}$ for the Sukhodol. 

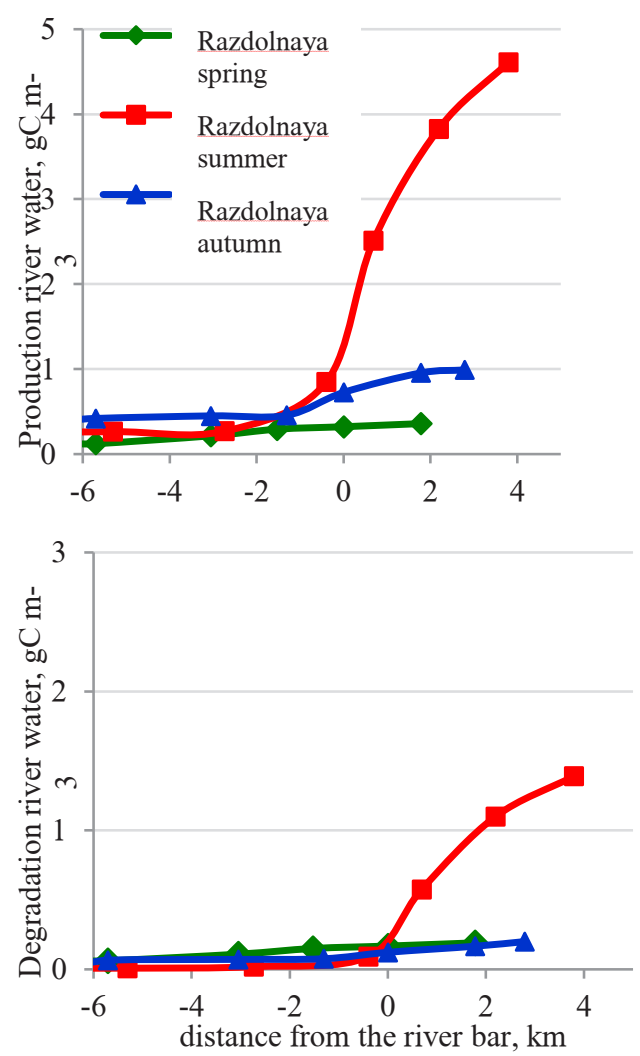
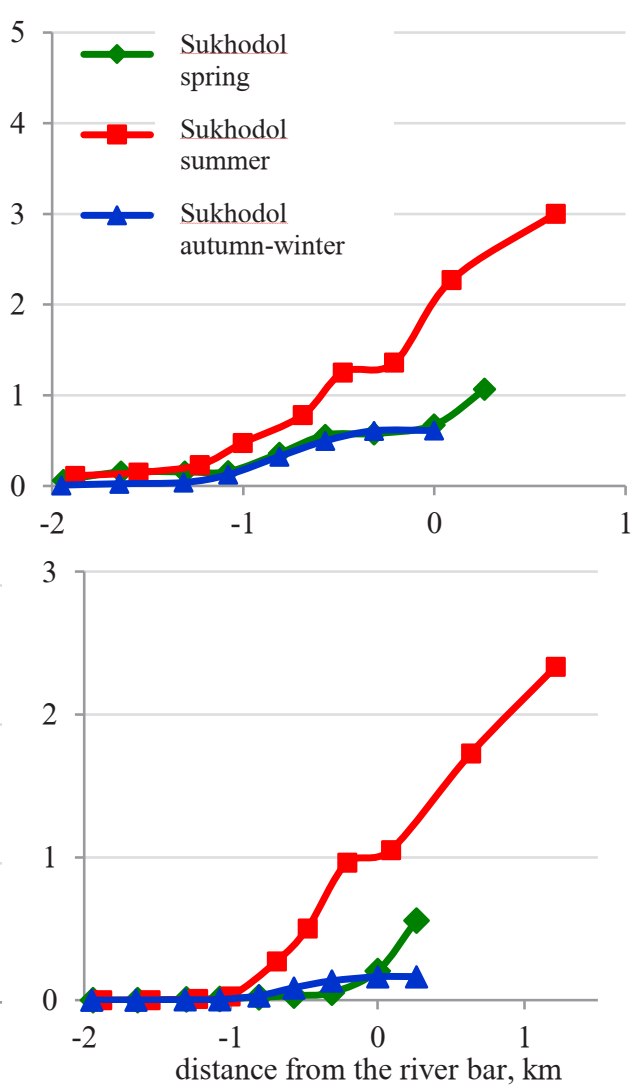

Fig. 6. Production and degradation from $1 \mathrm{~m}^{3}$ of the river water, averaged by season.
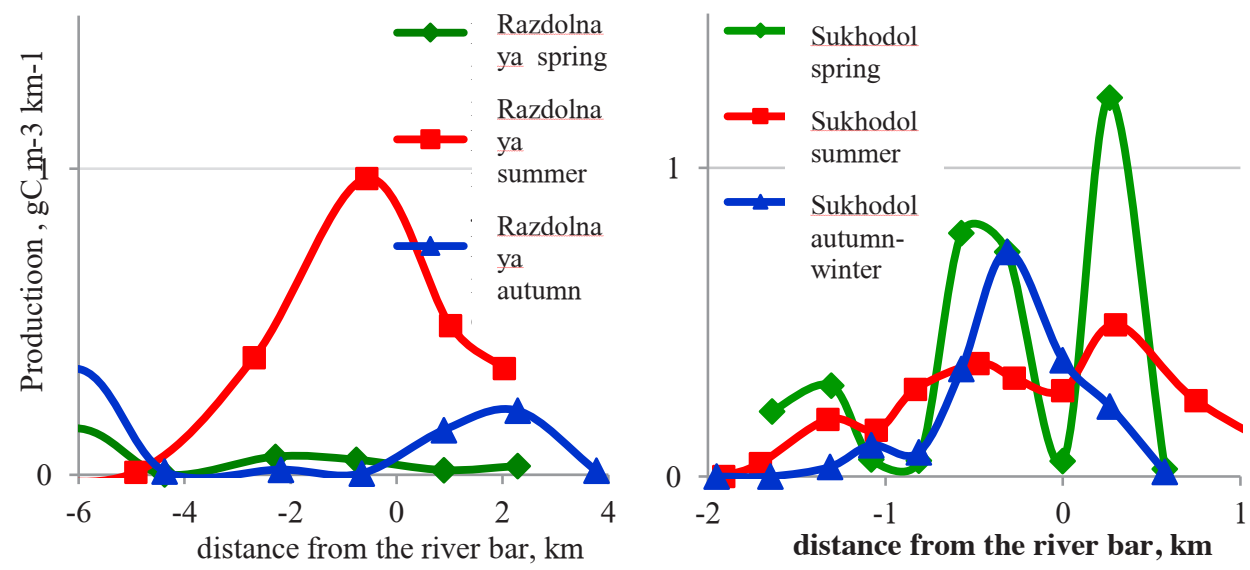

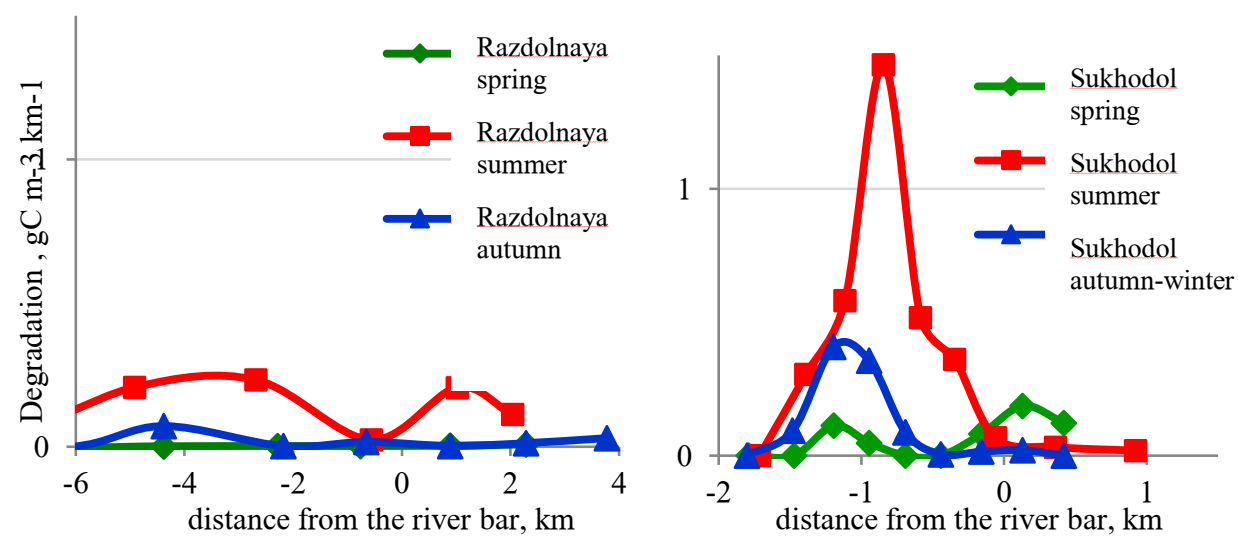

Fig. 7. Production and degradation values per a unit of estuary length, averaged by seasons.
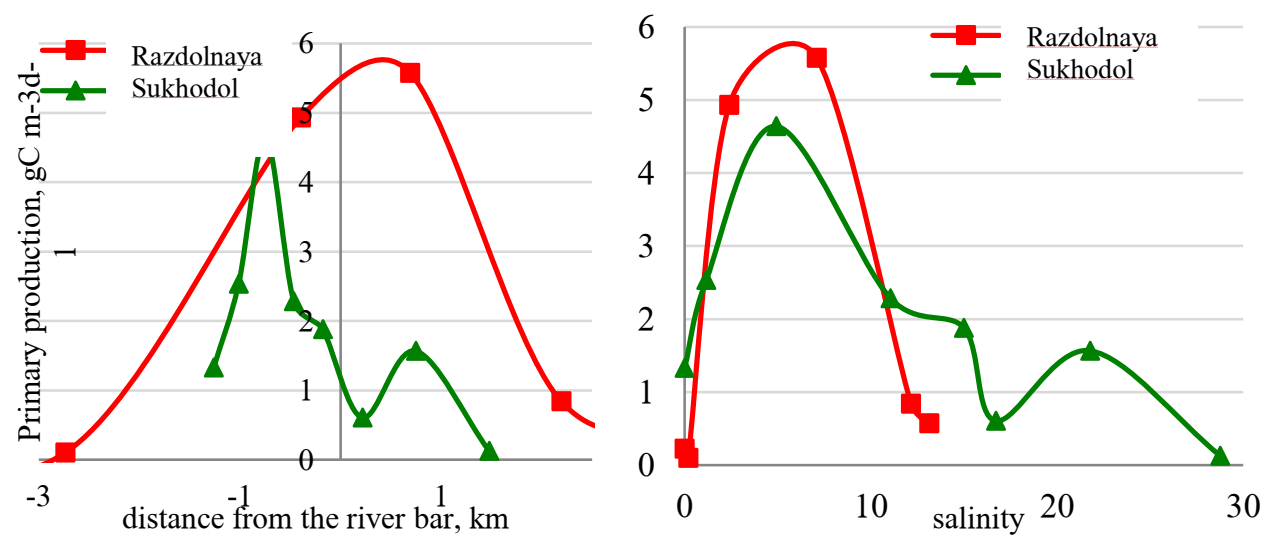

Fig. 8. Primary production along the estuaries (average for summer season).

\section{Discussion}

Contribution to production of the nutrients re-mineralized within the estuary was not estimated in earlier studies of estuarine productivity, where all nutrients detected in the estuaries were considered as terrigenous ones (Efimova, Tsitsarin, 2002; Zvalinsky et al., 2005; Lapin, 2011; Statham, 2012 ). The results of our research show that the estuaries are more than utilizers of terrigenous ion drainage, but also the sources of mineral forms of nutrients. The re-mineralized phosphorus transported from the internal estuary enhances considerably the nutrient supply in the brackish waters at the front between the internal and external zones located approximately at isohaline $\approx 13-17 \mathrm{psu}$.

High primary production of the Razdolnaya estuary in summer is caused by increasing of its water mineralization during the floods. On the contrary, mineralization of the Sukhodol water in summer is not high, but the relatively low concentration of terrigenous phosphorus is compensated here by active recycling within the estuary that ultimately provides more than a half of the production, whereas in the Razdolnaya estuary, its contribution to production never exceeds $20 \%$. Sometimes the recycled phosphorus can be seen directly as the local maximum of DIP at the front between the internal and external zones, where it is higher than in the river water upstream of the estuary (Fig. 4). 
Degradation per a unit of estuary length has the maximum in the internal zone of both estuaries, but it is significantly higher in the Sukhodol estuary, in particular in summer (Fig. $6)$.

Distribution of primary production along the salinity gradient is very similar for both estuaries: the maximum is located at the front between the internal and external zones (salinity 5-8 psu), usually in the upper part of the external zone. Position of the highest production belt relative to the river bar is different for two rivers: it locates seaward from the bar in the Razdolnaya, but riverward in the Sukhodol. Apparently, this difference is a result of the much higher water discharge of the Razdolnaya, which estuary extends far into the sea, while salinity increases very quickly in the Sukhodol estuary, where the front shifts upstream in summer with the sea level rise.

New estimates of primary production in the estuary of the Razdolnaya exceed the previous ones made by other methods (1.3-2.2 $\mathrm{gC} \mathrm{m}^{-3} \mathrm{~d}^{-1}$ from Zvalinskiy, Tishchenko, 2005). This is partially because of separate estimation of the production and decomposition instead of their sum and partially because of more detailed localization of the productive zone. The study reveals prominent spatial and temporal inhomogeneities of primary production within the estuary: along the salinity gradient and from season to season, it changes from zero to extreme values $>5 \mathrm{gC} \mathrm{m}^{-3} \mathrm{~d}^{-1}$, but the average values of primary production correspond to the levels known for other world estuaries, where assessments were made by various methods (from 0.5 to $6.0 \mathrm{gC} \mathrm{m}^{-3} \mathrm{~d}^{-1}$ : Krasnick, Caperon, 1973, Sorokin, Sorokin, 1996, Krishna Kumari et al., 2002, Moigis, Gocke, 2003, Cruzado et al., 2002; Golubkov et al., 2017; and others). Thus, the studied estuaries, as many other estuaries in the world, are eutrophic ecosystems.

The main patterns of the organic matter production and destruction in the Razdolnaya and Sukhodol estuaries are very similar. Both estuaries are the areas with the production predominance over destruction ones, seasonal changes of the production and destruction distribution along the water flow are also the same, despite the different water regime of these two rivers, which obviously means that these regularities have a common character. However, seasonal variations of the production and degradation are different between the estuaries because of specific features of their ionic discharge, though the highest values of net production are comparable for both estuaries $\left(0.8-1.0 \mathrm{gC} \mathrm{m}^{-3} \mathrm{~km}^{-1}\right)$.

These results correspond partially to the concept of estuaries as "marginal filters", where the terrigenous rivers discharge is disposed by nutrient consumption for photosynthesis (Lisitsyn, 1994; Telesh, Khlebovich, 2010). Despite the disadvantages, the results obtained using different approaches support generally the concept of Lisitsyn (1994) postulating that the most terrestrial nutrients are utilized in the process of photosynthesis in the external estuary. In the case of the Razdolnaya and Sukhodol, the filtering function dominates in spring; but in summer and fall, the opposite function of re-mineralization intensifies and the estuaries convert into "factories of nutrients" (Sapozhnikov et al., 2018). The filtering and mineralizing functions are spatially separated, and a considerable part of the re-mineralized phosphorus is consumed in the same estuary, which enhances its productivity.

\section{Conclusions}

Prominent variability of the production/degradation balance in space and time is revealed for two estuaries with different water regime, but patterns of this variability are similar between them: the organic matter degradation prevails in their internal parts, and its production dominates in their external parts, with a tendency of the production decreasing and degradation increasing, and the area of degradation extends from spring to autumn. 
Recycling of nutrients in the process of degradation promotes a significant heightening of production in the external estuaries over its potential value provided by terrigenous ionic flux from the rivers. These results allow combining two opposite concepts of the estuarine areas productivity and show that the estuaries are not only utilizers of terrigenous ionic runoff, but also sources of mineral forms of biogenic elements, or "marginal filter" and "factory of biogenes" at the same time. The destruction of organic matter coming from the river runoff is one of the important ecological functions of any estuary.

\section{References}

1. I.C. Azevedo, P.M. Duarte, A.A. Bordalo, Estuarine, Coastal and Shelf Science 69, 133-146 (2006)

2. T. Boonphakdee, T. Fujiwara, Environment Asia 1, 7-21 (2008)

3. V.D. Budaeva, Y.I. Zuenko, V.G. Makarov, Pacific Oceanography 6, 10-17 (2013)

4. G. Cabecadas, M. Nogueira, M.J. Brogueira, Marine Pollution Bulletin 38(I.12), 10921096 (1999)

5. J.M. Caffrey, M.C. Murrell, K.S. Amacker, J.W. Harper, S. Phipps, M.S. Woodrey, Estuaries and Coasts 37, 222-241 (2014)

6. J.E. Cloern, S.Q. Foster, A.E. Kleckner, Biogeosciences 11, 2477-2501 (2014)

7. A.Cruzado, Z. Velasquez, M. del C. Perez, N. Bahamon, N.S. Grimaldo, F. Ridolf, Continental Shelf Research 22, 349-360 (2002)

8. L.E. Efimova, A.G.Tsytsarin, Trudy GOIN (Proceedings of the State Oceanogr. Inst.) 208, 217-225 (2002)

9. B.D. Eyre, P.W. Balls, Estuaries and Coasts 22(2), 313-326 (1999)

10. S. Falco, L.F. Niencheski, M. Rodilla, I. Romero, J. Gonza, O. Lez Del Ri, J.P. Sierra, C. Moosso, Estuaries and Coastal Shelf Science 87, 92-102 (2010)

11. S. Golubkov, M. Golubkov, A. Tiunov, V. Nikulina, Journal of Marine Systems 171, 73-80 (2017)

12. I.R. Joint, A.J. Pomroy, Estuarine, Coastal and Shelf Science 13, 303-316 (1981)

13. G. Krasnick, J. Caperon, Pacific Science 27(2), 189-196 (1973)

14. L. Krishna Kumari, P.M.A. Bhattathiri, S.G.P. Matondkar, J. John, J. Marine Biology Association of India 44, 1-13 (2002)

15. S.A. Lapin, Voprosy promyslovoy okeanologii (Problems of Fishery Oceanography) 8(2), 83-100 (2011)

16. M.E. Lebo, J.H. Sharp, Estuarine, Coastal and Shelf Science, 35(I.3), 235-252 (1992)

17. A.P. Lisitsyn, Okeanologiya (Oceanography) 34, 671-682 (1995)

18. O.N. Lukyanova, S.A. Ireykina, A.P. Chernyaev, A.S. Vazhova, M.D. Boyarova, Russian Journal of Marine Biology 36(7), 489-496 (2010)

19. O.I. Mamaev, Thermohaline analysis of the World Ocean (Gidrometeoizdat, Leningrad 1987)

20. K. Grasshoff, K. Kremling, M. Ehrhardt, Methods of the seawater analysis (Weinheim, New York, Viley-VCH, 1999)

21. A.G. Moigis, K. Gocke, J. Plankton Research 25(10), 1291-1300 (2003)

22. A. Oczkowski, C.W. Hunt, K. Miller, C. Oviatt, S. Nixon, L. Smith, Estuaries and Coasts 39(6), 1827-1844 (2016) 
23. H.W. Paerl, K.L. Rossignol, N.S. Hall, B.L. Peierls, M.S. Wetz, Estuaries and Coasts 33, 485-497 (2010)

24. N.E. Pettit, R.J. Naiman, D.M. Warfe, T.D. Jardine, M.M. Douglas, S.E. Bunn, P.M. Davies, Ecosystems 20(3), 492-514 (2016)

25. A.C. Redfield, B.H. Ketchum, F.A. Richards, The Sea 2, 26-77 (1963)

26. V.V. Sapozhnikov, N.V. Arzhanova, N.V. Mordasova, Hydrochemistry and production-destruction processes in the White Sea. The Handbook of Environmental Chemistry (2018)

27. V.V.S.S. Sarma, V.R. Prasad, B.S.K. Kumar, K. Rajeev, B.M.M. Devi, N.P.C. Reddy, V.V. Sarma, M.D. Kumar, India. Continental Shelf Research 30(19), 2005-2014 (2010)

28. N.I. Savelyev, V.V. Anikiev, O.V. Dudarev, Variability of water stratification in the northern part of the Amur Bay of the Sea of Japan in summer. Status of marine ecosystems influenced by river runoff (Dal'nauka, Vladivostok, 2005)

29. P.Y. Semkin, P.Y. Tishchenko, N.D. Khodorenko, V.I. Zvalinskii, T.A. Mikhailik, S.G. Sagalaev, E.M. Shkirnikova, Water Resources 42(3), 352-361 (2015)

30. D. Shilla, M. Tsuchiya, D. Shilla, Chemistry and Ecology 27(6), 523-542 (2011)

31. Y. Sin, E. Lee, Y. Lee, K.-H. Shin, Estuarine, Coastal and Shelf Science 163, 279-289 (2015)

32. Y.I. Sorokin, P.Y. Sorokin, Estuarine, Coastal and Shelf Science 43(4), 399-418 (1996)

33. P.J. Statham, Science of the Total Environment 434, 213-227 (2012)

34. R.W. Sterner, J.J. Elser, Ecological stoichiometry: the biology of elements from molecules to the biosphere (Princeton Univ. Press, 2002) http://books.google.com/

35. A. Süzal, N. Bizsel, K.C. Bizsel, Y.S. Hüsrevoğlu, Turkish Journal of Engineering and Enviromental Sciences 32, 67-84 (2008)

36. I.V. Telesh, V.V. Khlebovich, Marine Pollution Bulletin 61(4-6), 149-155 (2010)

37. G.J.C. Underwood, J.C. Kromkamp, Advances in Ecological Research 29, 93-153 (1999)

38. A.S. Vazhova, Y.I. Zuenko, Izvestia TINRO (Newsletters of Pacific Fish. Res. Center) 182, 132-143 (2015)

39. V.I. Zvalinsky, A.P. Nedashkovsky, S.G. Sagalaev, P.Y. Tishchenko, M.G. Shvetsova, Marine Biology 31(2), 107-116 (2005)

40. V.I. Zvalinsky, P.Y. Tishchenko, Nutrients in the estuaries: behavior and biogeochemistry. Status of marine ecosystems influenced by river discharge (Dal'nauka, Vladivostok, 2005) 